\title{
Impact of Information and Communication Technology on Logistics Industry: An Analysis
}

\author{
Abhishek Tiwari \\ Lecturer, Department of logistics, Faculty of Business Administration St. Theresa International College, Thailand.
}

\section{Abstract}

The e-commerce industry in India is growing as fast, as booming, and as expanding at a larger rate. The concept of online shopping has attracted the Indian population tremendously. Exposure to information and communication technology has been highly instrumental in e-commerce success.After the development pertained to technology, science, and information, ICT has virtually become a companion in the life of people. In emerging economies like India, the majority ofInternet users are under the age of 35, a number that is significantly higher thanthat of the developed economies. This age group loves to shop and has grown as asignificant buying group that has crossed the number of 700 million internet consumers by 2020 . The huge size of the customer base of the young generation has brought a significant revolution in all industries undoubtedly. The earning capability of this generation is also expected to makethe young generation an important consumer after they enter the workforce. The workforce analytics has also shown the proven data of usage of internet among youngsters and growing industries like logistics. Togain long term success, online retailers must involve young consumers whoare technologically savvy and have significant purchasing power (Hanford, 2005).As Logistics ensures the movement of goods/services from one place to another place, the fulfillment of its main objective wholly lies on the technology which maps that the right product reaches the right person at the right time at the right place in the right condition and the right cost. Mobile devices working across

the world proves this point.

ArticleReceived:10August2Revised:25October 2020 Accepted: 18 November 2020

In the recent time-frame, during the crisis spread out by Covid-19 too, ICT has helped the civilization to sustain from home to live a life full of groceries and essentials. To a great extent,the world is indeed surviving today on two versatile sectors - Logistics and Information Technology (IT). It is apprehensive for both social and economic scenarios worldwide. To survive, people/businesses, either their requirements should reach them or they should reach their requirements. Either way, it involves the movement of the requirements, thus logistics and ICT provide the best of its outcomes through the availability of products to consumers.It is said that the $18^{\text {th }}$ $19^{\text {th }}$ century belonged to the industrial revolutionand the $20^{\text {th }}$ to technological intervention, sci-technology with multimedia inventions, $21^{\text {st }}$ to medicine and ICT only. Thus the present era has been addressed asthe the sector to new heights. It has made the world a 'global village'. It is only thegeographical distance that matters now. The present research area will be covered throughout the empirical research on the select logistics industry with the fundamental approach to ponder over the working systems, specifically ICT, and its development in the present times. The present research paper is an attempt to gather research data for the young researchers and beginner professionals to perceive the usage of ICT in the Logistics industry universally. It is empirically gathered and genuine references have been cited.

Role and Development of ICT in the Logistics industry

Logistics has been an integral part of global development for close to 5000 years. More oftenthan ever, intelligent logistics solutions have been the basis for the transformation to a newhistorical and economic 
era. The creation of large to very large cargo vessels on the oceans andseas has been the novel service systems so far during the 20th century that has witnessed thisbasic progress. Both these are an integral part of the current scenario in globalization. There are quite a few initiatives taken by the organization/s to reduce this chaos by adoptingtechnology. But this is not enough to look at the kind of dependency this sector possesses of. Some organizations have compulsorily adapted to technology, for example, GPS to track their vehicles. Still, there is much to ponder over in the same field.

ICT may affect the working structure of any organization and it enhances the mass coverage of work technologically and in a proven righteous manner. Porter and Millar (1985) argue that ICT affect the competition in three distinct ways: (i) ICT may change the structure of an industry, and modify the rules of competition; (ii) ICT may be used to create sustainable competitive advantage and provide firms with new competitive instruments; and (iii) ICT new business may be developed within a firm's existing activities.At this level of understanding of the context, we may see the current examples from reliability of customers throughout the globe on e-shopping websites.

In this context, ICT application may be a useful tool that allows a firm to achieve this aim because of the potentially high information intensity in the firm value chain. According to Porter (2001), the basic tool for understanding the influence of ICT on firms is the value chain - the set of activities through which a product or service is created and delivered to customers. When a firm competes in any industry, it performs several discrete but interconnected valuecreating activities, such as operating a sales force, producing a component, or delivering products, and these activities have points of connection with the activities of suppliers, channels, and customers. The value chain is a framework for identifying all these activities and analyzing how they affect both the costs faced by firms and the value delivered to buyers. Also, every activity involves the creation, processing, and communication of information, ICT has a pervasive influence on the value chain. The special advantage of the Internet is the ability to link one activity with others and make real-time data created in activity widely available, both within the firm and with outside suppliers, channels, and customers. Today, firms frequently integrate Internet technology to redesign processes in ways that strengthen their competitive advantages. A business firm can gain a competitive advantage by operational effectiveness, doing the same as your competitors do but doing it better, and by strategic positioning, doing things differently from competitors in a way that delivers a unique type of value to customers.According to Rashid and Al-Qirim (2001), four factors interact within a firm and serve as an evaluative structure to determine the propensity of innovation adoption specific to the firm and thereby directly impacting the CEO's decision process: (i) Individual factors: incorporate the decision maker's innovativeness and their knowledge of technology that affect innovation adoption; (ii) Organisational factors: influencing adoption cover such aspects as the size of the firm, the quality of the existing information systems, the intensity of the information being processed, the level of specialization of the firm as well as the level of adoption that is provide by the CEO's; (iii) Technological or innovation factors: include issues such as the relative advantages of the innovation, the complexity, the compatibility, cost and the image surrounding the innovation; (iv) Environmental factors: impacting adoption include the pressure from competition and within the supply chain, public policy as well as the role of government. Rashid and Al-Qirim (2001) indicate that any or all four factors may impact on the process of ICT adoption. The organizational factors collectively impact the resources of the business concerningthe adoption of ICT innovation. Environmental factors provide significant impetus for adoption where the issues relating to market climate and the firm's standing in the market directly influence the uptake of technology. Increases in the incorporation of ICT within-firm directly impacts on the functionality of the firm, increasing productivity and profitability of the business. Individual factors incorporate the management aspects attributed to the business and thereby influence significantly any decision to enhance the performance of the business. To add, the levels of ICT adoption by firms need to be addressed in terms of an evolutionary process. The evolution of E-business for firms has been described in the contemporary 
literature illustrating the transition from email use, website, online store, then to a digital basis for fully ebusiness commonly identified as progress. The evolution of a firm is established in evolution stages starting with limited use of technology through to the full integration of business automated processes as seen in the digital firm.

\section{Challenges of ICT in Logistic industry}

With usage and comfort, the challenges take place in the same way. Within the expansion of ICT in the Logistics industry, the companies face multiple challenges too. It is the role of reducing transportation cost, improving supply chain visibility, supply chain finance, improving business process for customer/s, and, government regulations and sustainability. Whether, business intelligence is the ability to transform data into information and information into knowledge as a way to optimize the decision-making process in companies. The fundamental role of suppliers is to lower purchasing costs, improve products' quality and reduce the stock and delivery times. In this logistics activity, the electronic exchange of information with trust relationships between suppliers and customers enables an auto-billing from the consumption made, to develop automatic orders to suppliers, to join charging needs with the availability of carriers as well as to standardize the information through the same selection criteria. To keep the planning of the whole supply chain of a company synchronized, it is used the so-called forecasting, that is to say, performing an estimation of future demand for a product, to improve the flow of the information in the supply chain and thereby, prepare the different areas of the company for future operations. The main benefits are:

- Improved availability, through the revision and the control of demand.

- Improved predictions.

- Control inventory levels to reduce the effects of peak demand.

- It complements the assessment of postpromotions.

- It improves the order fulfillment process by reducing the planning cycle.
In Indian markets, realizing the need of a controlled ETA of arrival of the shipments with accuracy and also the need to mobilize the workforce and connected departures, the company installed GPS and GPRS technology to receive the actual location of the trucks from a fitted device. The installation of the devices gives information as web services on every 15 minutes from the GPS service providers which have been integrated into the core ERP system. Real-time analytics run on the information provided by GPS and cargo information from the ERP to plan automatically for onward connections for cargo which earlier used to be manually driven with judgements of hub managers. This visualization can be seen with an analytics visualization tool called TibcoSpotfire which is accessible from multiple devices. An android app has been created for hub managers to see real time arrival dashboard and can plan for onwards cargo movements based on recommendation. Hub managers can use this application to get all the information for tracking, truck arrival, departure, exceptions on the warehouse floors without even need to go to office. Other than this, poor infrastructure, customer nuances and lack of transparency are the major concerns in the said.

\section{The level of implementation of ICT in the Logistics industry}

The impact of Information and Communication Technologies on logistics In the ICT logistics approach embraces the hardware, the software, and the networks investment and the design to facilitate processing and exchange of data. The direct impact upon logistics organizations of the future may be a reduction in formal structure with an increase in the networking of specialists. Executives at many firms have realized that it is no longer necessary to maintain total internal control over all phases of operations. Logistics strategies can be implemented and performance goals realized through closer interactions and boundaryspanning relationships with trading partners. The adoption of adequate ICT could make it possible. The introduction of ICTs in logistics has enabled improvements in the management, control, and constant monitoring of goods either at different times of storage or in various stages of transport, from the point of manufacture or origin to the point of final consumption. ICTs lead to the increase of the 
efficiency and speed of the processes involved in logistics activities as well as minimizes the possible errors during data processing, some of them of human origin.

In Indian companies, for example,"Safexpress" has also installed airport style vehicle arrival LED screens which are connected to the GPS in real time. There are geo-fencing around the warehouses, so when trucks are reaching in the periphery of warehouse, the unloading preparedness action starts on the warehouse floor right away. This installation helped a lot in workforce mobilization while improving the workforce productivity. Analytics based on cargo connection is also helping Safexpress improve the load factor of vehicles while the overall transit time is continuously improved cutting down the delays drastically. Moreover, the visibility for hub managers also improved to a great extent as well asvehicle actual ETA. Hub managers can track all the information about the vehicles and can make better decisions based on the analytical data.

Suggestions to propound the framework for the better usage of ICT in Logistic organizations

In recent times several changes occurred that have highlighted the importance of logistics either as a source of competitive advantage, or as a crucial strategy. This means higher customer satisfaction and also bigger success for firms. Some of the referred changes are associated with the business globalization, the continuous shortening of products life cycle, the intensification of competition, and the appearance of new competitive priorities. The importance of logistics and its related functions, which move products, orders, and data along many dispersed points (production plants, warehousing, retailing, and transportation), increases the firms' concern, in terms of accompanying, controlling and managing distinct logistical operations. Through the intensive use of Logistics' ICT, namely, acquisition, communication, and identification technologies, the information flows are, efficiently, used by firms, in order to reinforce the existent competitive advantages, or alternatively, to create new competitive advantages. In this paper a conceptual model for the adoption of Logistics' ICT is presented, by taking into consideration four determinant factors: individual, organizational, technological or innovation and environmental. The interaction established between the referred determinant factors may be identified through the computation of the predominant factor, by using a selected set of adequate indicators and a simple geometry methodology. These procedures may provide the identification of the predominant factor that determines the firms' competitive advantages, which are originated from the adoption of Logistics' ICT. Finally, in terms of guidelines for future researches, we suggest the development of longitudinal studies, which may conjoin three theoretical approaches, namely, the firms' life cycle, the logistics' ICT and competitiveness. In this sense, taking into consideration the conceptual model now proposed, future studies may be developed in order to identify the dominant factors that determine the competitive advantages obtained through the Logistics' ICT adoption, according to each stage of firms' life cycle. It comprises of many companies need to store their products and are under pressure on reducing costs and inventories, these pressures are greater as time goes by. This leads many companies to seek new methods to make their warehouse operations more competitive than before. Currently, the structure and functions of the stores are subject to a process of change due to the speed of communications, the growth of electronic commerce and the presence of customers on the Internet. The key to achieve competitive advantages and better results in warehouses are flexibility, speed, accuracy and immediacy of information, which can be easily obtained by using different technologies Automatic Identification and Data Capture (AIDC) combined with Warehouse Management Systems (WMS). Degree Final Dissertation - Course 2015/2016 15 WMS offer the user a real-time view of the supply chain of a company, with the aim of improving its control, the process of decision making and customer service levels. Besides, other functions of these systems are the management of the main processes taking place in the warehouse of a company, such as, inventory management and control of the flow of goods from before their receipt until after their delivery. The Warehouse Management Systems manage product locations and movements of workers and machines responsible for the maintenance of items. On the other contrary, the WMS have two types of optimization mechanisms, one dedicated to optimize 
storage space, through a proper management of locations, and one that optimizes material movements, whether they are made by machines or people. The introduction of ICT in warehouse management is a new way of working, faster and more effectively. Once applied these types of systems, they result in a number of very representative results in companies: the productivity of the company increases, as equipment and staff are controlled in real time, increased accuracy of the goods due to automatic identification, reducing inventory levels and safety stock, optimization of warehouse space, thanks to real-time control of inventory management, improvements in the management and control tasks to facilitate planning and monitoring, reduction of administrative work, and improvements in the level of customer service.

To summarize, it can be said that the role of information and communication technology is evitable in logistics industry. It shall be comprehended with a few suggestive adaptations for the effective results in the said industry. Automation of packaging, updated shipment tracking system, usage of analytical software available in Indian market, and adaptation towards more security measures are needed for the efficacy, accuracy and universality of the industry to grow in more hands.

\section{References:}

Bhatt, G. D., \& Grover, N. (2005). Types of information technology capabilitiesand their role in competitive advantage: An empirical study. Journal ofManagement Information Systems, 22(2), 253-277.

P. V. Sathya Gopal, K. Shireesha\& N. P. EswaraReddy , "Attitude of The Faculty Members Towards Information and Communication Technology (ICT) in State Agricultural Universities “, International Journal of Educational Science and Research (IJESR), Vol. 8, Issue 2, pp. 13-18

Gill Press, Managing Parner, gPress, A Very Short History of Information Technology(IT), April 2013.

Satar Habib Mnathr, AbdullhSaiwanMajli\&InasAnouarFarhoud, "The Exploration of Bioenergy Generator Processing Based on the Information and Communication Technology ", International Journal of Mechanical and Production Engineering Research and Development (IJMPERD), Vol. 8, Issue 6, pp. 359-364
Hussein S. Lidasan and Marilyn H. Obogne, 2005, A Study on The Impact ofInformation And Communication Technology On Urban Logistics System Journal of theEastern Asia Society for Transportation Studies, Vol. 6, pp. 3005 - 3021, 2005.

V. Hemavathy\& S. SaradhaDevi, "Assertive Communication “, BEST: International Journal of Humanities, Arts, Medicine and Sciences (BEST: IJHAMS), Vol. 4, Issue 1, pp. 119-126

Legris, P., Ingham, J., \&Collerette, P. (2003). Why do people use informationtechnology? A critical review of the technology acceptance model. Information\& management, 40(3), 191-204.

Uchebo, Samuel Yahaya\&AminuSanni, "Impact of Information and Communication Technology (ICT) On Distance Learning Programme of National Teachers' Institute, Dekina Study Centre: Implications for Counselling “, International Journal of Electronics and Communication Engineering (IJECE), Vol. 7, Issue 2, pp. 1-8

RémiFounou, 2002, The Role of IT in Logistics: Competitive Advantage Or StrategicNecessity? 2nd Swiss Transport Research Conference, Monte Verità / Ascona 2002,Session Logistics.

Ward, J. C., \&Ostrom, A. L. (2003). The internet as information minefield: ananalysis of the source and content of brand information yielded by netsearches. Journal of Business research, 56(11), 907-914.

Manisha Tharu\& Ram Ganesh Yadav, "Effects of Technological Development through Electronic Communication in Women Empowerment ", International Journal of Humanities and Social Sciences (IJHSS), Vol. 7, Issue 5,pp. 93-100

CH. V. Phani Krishna \& S. V. Swamy, "The Ubiquitous Wireless Communication that Ropes Mobile Devices “, BEST: International Journal of Management, Information Technology and Engineering (BEST: IJMITE), Vol. 3, Issue 10, pp. 101-110

Williams, M. D., Dwivedi, Y. K., Lal, B., \& Schwarz, A. (2009). Contemporarytrends and issues in IT adoption and diffusion research. Journal of InformationTechnology, 24(1), 1-10.

\section{Online resources:}


http://www.journalijar.com/uploads/744_IJAR-

15667.pdf

https://core.ac.uk/download/pdf/61487246.pdf

https://porter.in/about-us

https://pdfs.semanticscholar.org/b530/fcc9a266d5cc

a9027bdb2882ce08fd96c22a.pdf

https://hal.archives-ouvertes.fr/hal-

02386986/file/ASSAR-ICT_and_Education.pdf 